\title{
INFLUÊNCIA DA COBERTURA MORTA E DA ADUBAÇÃO NO CONTROLE DA PODRIDÃO RADICULAR EM MUDAS DE CITROS (Phytophthora nicotianae)
}

\author{
Tiago Alexandre Silva ${ }^{1}$, Edna Peixoto da Rocha Amorim², José Paulo Vieira Costa², Maryllia Gabriella Silva \\ Costa $^{1}$, David Vitor Santos ${ }^{1}$ \\ 'Universidade Estadual Paulista, UNESP, Botucatu,SP. ${ }^{2}$ Centro de Ciências Agrárias, Universidade Federal de Alagoas, BR 104 Norte, \\ Km 85, Rio Largo, AL. \\ *Autor para correspondência: Edna Peixoto da Rocha Amorim, ednaamorim58@hotmail.com
}

RESUMO: Estudou-se o efeito de resíduos orgânicos e da adubação com Cálcio (Ca) e Potássio (K) no controle da podridão radicular em mudas de citros (Phytophthora nicotianae), doença responsável por grandes perdas na citricultura. Como cobertura morta utilizou-se casca de feijão, casca de mandioca, folhas de couve e bagaço de cana em vasos com substrato inoculado com uma suspensão de inóculo de $P$. nicotianae (20 esporângios. $\left.\mathrm{mL}^{-1}\right)$, na proporção de $20 \mathrm{~mL} /$ vaso. Substrato descoberto e o fungicida metalaxyl foram utilizados como testemunhas. Cada vaso recebeu uma muda de citros com raízes previamente feridas. 0 delineamento foi inteiramente casualizado com seis tratamentos e oito repetições. No ensaio de adubação, procedeu-se uma análise de solo para recomendação da adubação com Ca e K. Foram utilizadas as doses de sulfato de cálcio: 480 mg. $\mathrm{L}^{-1} ; 600$ mg. $\mathrm{L}^{-1} ; 720 \mathrm{mg} \cdot \mathrm{L}^{-1} ; 360 \mathrm{mg} \cdot \mathrm{L}^{-1} ; 240 \mathrm{mg} . \mathrm{L}^{-1} ;$ fosfato de potássio: 94mg. $\left.\mathrm{L}^{-1}\right) ; 117,5 . \mathrm{L}^{-1} ; 141 \mathrm{mg} . \mathrm{L}^{-1} ; 70,5 \mathrm{mg} . \mathrm{L}^{-1} ; 47 \mathrm{mg}$. $\mathrm{L}^{-1}$; combinação das doses de cálcio e potássio e o solo sem adubação (testemunha). 0 substrato foi adubado e colocado em vasos, semeados com 2 sementes de citros. Dez dias após a germinação, a adubação foi repetida. $O$ patógeno foi inoculado nas plântulas (30 dias) pelo método da agulha. Utilizou-se um delineamento inteiramente casualizado com dezesseis tratamentos e quatro repetições. Após 60 dias foram observados a incidência da doença e o desenvolvimento das mudas. Os resultados foram comparados pelo teste de Tukey $(P=0,05)$. As coberturas mortas apresentaram capacidade de controlar a podridão radicular, destacando-se folha de couve e bagaço de cana (100\%), casca de feijão e casca de mandioca (>75\%). Os tratamentos que foram adubados com dose de $480 \mathrm{mg} \cdot \mathrm{L}^{-1}$ de cálcio e a combinação de potássio e cálcio (360 mg. $\mathrm{L}^{-1}+70,5 \mathrm{mg} \cdot \mathrm{L}^{-1} \mathrm{e} 240 \mathrm{mg} \cdot \mathrm{L}^{-1}+47 \mathrm{mg} \cdot \mathrm{L}^{-1}$ ) tiveram uma eficácia contra a doença de $100 \%$. Os tratamentos demonstraram eficiência em reduzir a incidência da doença em mudas de citros.

PALAVRAS-CHAVES: Citrus sp., controle alternativo, oomiceto

\section{INFLUENCE OF MULCHING AND FERTILIZATION IN THE CONTROL OF CITRUS ROOT ROT (Phytophthora nicotianae)}

\begin{abstract}
We studied the effect of organic waste and fertilization with calcium $(\mathrm{Ca})$ and potassium $(\mathrm{K})$ in the control of root rot in citrus seedlings (Phytophthora nicotianae), a disease responsible for major losses in the citrus industry. As mulch was used bean husk, cassava peel, cabbage leaves and bagasse in pots containing

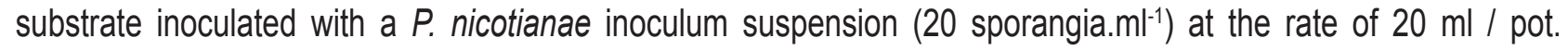
Substrate discovered and the metalaxyl fungicide was used as witnesses. Each pot received a change of citrus with previously injured roots. The design was completely randomized with six treatments and eight repetitions. In the fertilizer experiment, we proceeded to a soil analysis for recommendation fertilization with $\mathrm{Ca}$ and $\mathrm{K}$. Calcium

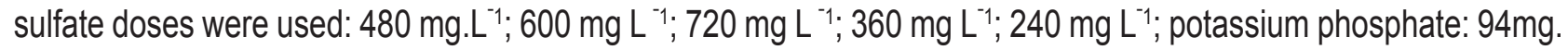
$\mathrm{L}^{-1} ; 117,5 . \mathrm{L}^{-1} ; 141 \mathrm{mg} . \mathrm{L}^{-1} ; 70,5 \mathrm{mg} . \mathrm{L}^{-1} ; 47 \mathrm{mg}^{-\mathrm{L}^{-1}}$; combination of calcium or potassium fertilization and soil without fertilization (control). The substrate was fertilized and placed in pots, seeded with 2 citrus seed. Ten days after germination, fertilization was repeated. The pathogen was inoculated in seedlings ( 30 days) by the method of the needle. We used a completely randomized design with four replications and sixteen treatments. After 60 days were observed disease incidence and development of seedlings. The results were compared by Tukey test $(P=0.05)$. The mulches showed ability to control root rot, especially leaf of cabbage and sugar cane bagasse (100\%), bean
\end{abstract}


and cassava (> 75\%). The treatments were fertilized with a dose of $480 \mathrm{mg} \cdot \mathrm{L}^{-1}$ calcium and the combination of potassium and calcium ( $360 \mathrm{mg} \cdot \mathrm{L}^{-1}+70,5 \mathrm{mg} \cdot \mathrm{L}^{-1}$ and $240 \mathrm{mg} \cdot \mathrm{L}^{-1}+47 \mathrm{mg} \cdot \mathrm{L}^{-1}$ ) had efficacy against to $100 \%$ disease. The treatments demonstrated effectiveness in reducing the incidence of the disease in citrus seedlings.

KEYWORDS: Plant disease, alternative control, oomycete

\section{INTRODUÇAO}

A citricultura representa um importante segmento na estrutura socioeconômica do Brasil, podendo ser constituída como uma das mais típicas atividades agroindústrias. A importância brasileira, como produtora de citros, está focada principalmente na laranja, que garantem os títulos de maior produtor mundial e de maior exportador de suco concentrado ao Brasil. 0 cultivo de frutas cítricas é realizado em todas as regiões do país, destacando os estados de São Paulo, Bahia, Sergipe e Minas Gerais (IBGE, 2011).

A produtividade da cultura dos citros tem sido reduzida por problemas fitossanitários. Entre as várias doenças de importância econômica, destaca-se a gomose de Phytophthora (Castro, 2009), que pode se expressar de diferentes formas causando grandes perdas. Os sintomas podem variar dependendo da espécie ou cultivar de citros, da idade da planta, dos órgãos onde ocorre o ataque ou das condições ambientais prevalecentes. Em viveiros, o fungo pode atacar os tecidos da região do colo das plantinhas, com lesões deprimidas de cor escura que aumentam de tamanho e acabam provocando a morte das mudas. 0 fungo pode ainda infectar sementes e causar podridões antes mesmo da germinação (Neves, 2011).

A podridão radicular, causada por Phytophthora spp., pode ser controlada pelo uso de fungicidas sistêmicos (Feichtenberger et al., 2005). Porém, uma boa nutrição das plantas e o uso de cobertura morta que ajude a manter a produtividade e sanidade das raízes também pode auxiliar na restrição ao desenvolvimento da doença.

O uso da cobertura morta no manejo das doenças causadas por patógenos radiculares além de contribuir como barreira física contra patógenos, mantém a umidade do solo, controla ervas invasoras, diminui a lixiviação de nutrientes e desenvolve a microbiota antagonista (Zauza et al., 2001).

A adubação com cálcio e potássio é outra possibilidade de controle da podridão radicular, tendo em vista que a presença do cálcio, nos tecidos vegetais, normalmente, diminui a ocorrência de doenças, devido a sua relação com o metabolismo das pectinas. Árvores submetidas a um programa de adubação com o uso de nitrato de cálcio demonstraram baixa incidência de Podridão radicular (Phytophthora spp), especialmente quando comparado ao uso de sulfato de amônio e ureia (Pipolo, 1993) e plantas adubadas com níveis suficientes de potássio são mais resistentes, devido a modificações na permeabilidade diferencial das membranas celulares pela mudança na relação K:Ca (Huber e Arny, 1985), além de serem capazes de acelerar o processo de lignificação das células esclerenquimáticas, aumentando a espessura da parede celular (Marschner, 1995, 1996).

Dessa forma o propósito deste trabalho foi selecionar cobertura vegetal e doses de potássio e cálcio capazes de promover o crescimento de plântulas de citros e controlar a podridão radicular, causada por P. nicotianae.

\section{MATERIAL E MÉTODOS}

Os experimentos foram desenvolvidos no laboratório de fitopatologia e na casa de vegetação do Centro de Ciências Agrárias, da Universidade Federal de Alagoas, durante o período de agosto de 2013 e julho de 2014.

\section{Obtenção do isolado de Phytophthora}

$O$ isolado de $P$. nicotianae foi obtido da coleção de microrganismo do Laboratório de Fitopatologia, do Centro de Ciências Agrárias, da Universidade Federal de Alagoas (CECA/UFAL). O patógeno foi repicado para placas de Petri com meio CDA (Cenoura-dextroseágar) e cultivado em condições ambientais $\left( \pm 28^{\circ} \mathrm{C}\right)$ por sete dias.

\section{Obtenção das mudas de citros}

Sementes de citros da cultivar "limão doce" foram adquiridas do pomar do CECA, as mesmas foram coletadas e tratadas para a produção de 
mudas sadias. As sementes foram desinfestadas com hipoclorito de sódio $2 \%$, álcool $70 \%$ e água destilada esterilizada e foram postas em um papel toalha para reter a umidade. Foram semeadas duas sementes de citros em cada cédula de uma bandeja, posteriormente estas mesmas cédulas foram preenchidas com solo de barranco esterilizado. Após a germinação das sementes, procedeu-se o transplantio para vasos $(400 \mathrm{~mL})$ contendo substrato esterilizado, constituído por solo + fibra de coco + torta de filtro de cana-deaçúcar (2:1:1).

\section{Bioenasios}

\section{Influência da cobertura morta sobre a podridão radicular ( $P$. nicotinae) e desenvolvimento das mudas de citros:}

As plântulas de citros, com 30 dias de idade, tiveram suas raízes feridas e foram transplantadas para substrato infestado com uma suspensão de inóculo de P. nicotianae (20 esporângios. $\mathrm{mL}^{-1}$ ), na proporção de $20 \mathrm{~mL} / v a s o$. Em seguida, o substrato foi coberto com resíduos vegetais, previamente desidratados a $55^{\circ} \mathrm{C}$ por $48 \mathrm{~h}$ e triturados, formando uma camada de $3 \mathrm{~cm}$ de espessura.

Utilizou-se como resíduos vegetais: casca de feijão (CF), casca de mandioca (CM), folhas de couve (FC) e bagaço de cana (BC). As testemunhas foram constituídas por fungicida (metalaxyl $-250 \mathrm{mg}^{-\mathrm{L}^{-1}}$ ) e substrato infestado sem cobertura vegetal. Foi utilizado um delineamento inteiramente casualizado com seis tratamentos e oito repetições.

As avaliações da incidência da doença e desenvolvimento das mudas foram realizadas após 60 dias. Os dados foram submetidos à análise de variância e as médias comparadas pelo teste de Tukey $(P \leq 0.05)$.

Efeito de doses de cálcio e potássio sobre a podridão radicular ( $P$. nicotinae) e desenvolvimento das mudas de citros:

Procedeu-se uma análise de solo para recomendação da adubação com $\mathrm{Ca}$ e K. Foram utilizadas diferentes doses de sulfato de cálcio $\left(\mathrm{CaSO}_{4} \cdot 2 \mathrm{H} 2 \mathrm{O}\right)$ e fosfato de potássio (KH2PO4), combinadas ou não (Tabela 1).
Tabela 1. Fonte e doses de Cálcio e potássio utilizados no experimento

\begin{tabular}{ll}
\hline Fonte & Dose (mg. - $\left.{ }^{-1}\right)$ \\
\hline $\mathrm{CaSO}_{4} 2 \mathrm{H}_{2} \mathrm{O}$ & $480 \quad($ Dose recomendada- DR) \\
$\mathrm{CaSO}_{4} 2 \mathrm{H}_{2} \mathrm{O}$ & $600 \quad(+25 \%)$ \\
$\mathrm{CaSO}_{4} 2 \mathrm{H}_{2} \mathrm{O}$ & $720(+50 \%)$ \\
$\mathrm{CaSO}_{4} 2 \mathrm{H}_{2} \mathrm{O}$ & $360(-25 \%)$ \\
$\mathrm{CaSO}_{4} 2 \mathrm{H}_{2} \mathrm{O}$ & $240(-50 \%)$ \\
$\mathrm{KH}_{2} \mathrm{PO}_{4}$ & $94($ Dose recomendada $)$ \\
$\mathrm{KH}_{2} \mathrm{PO}_{4}$ & $117,5(+25 \%)$ \\
$\mathrm{KH}_{2} \mathrm{PO}_{4}$ & $141(+50 \%)$ \\
$\mathrm{KH}_{2} \mathrm{PO}_{4}$ & $70,5(-25 \%)$ \\
$\mathrm{KH}_{2} \mathrm{PO}_{4}$ & $47(-50 \%)$ \\
$\mathrm{CaSO}_{4} 2 \mathrm{H}_{2} \mathrm{O}+\mathrm{KH}_{2} \mathrm{PO}_{4}$ & $480+94(\mathrm{DR} \mathrm{Ca}+\mathrm{DR} \mathrm{K})$ \\
$\mathrm{CaSO}_{4} 2 \mathrm{H}_{2} \mathrm{O}+\mathrm{KH}_{2} \mathrm{PO}_{4}$ & $600+117,5(+25 \% \mathrm{Ca}+25 \% \mathrm{~K})$ \\
$\mathrm{CaSO}_{4} 2 \mathrm{H}_{2} \mathrm{O}+\mathrm{KH}_{2} \mathrm{PO}_{4}$ & $720+141 \quad(+50 \% \mathrm{Ca}+50 \% \mathrm{~K})$ \\
$\mathrm{CaSO}_{4} 2 \mathrm{H}_{2} \mathrm{O}+\mathrm{KH}_{2} \mathrm{PO}_{4}$ & $360+70,5 \quad(-25 \% \mathrm{Ca}+-25 \% \mathrm{~K})$ \\
$\mathrm{CaSO}_{4} 2 \mathrm{H}_{2} \mathrm{O}+\mathrm{KH}_{2} \mathrm{PO}_{4}$ & $240+47(-50 \% \mathrm{Ca}+-50 \% \mathrm{~K})$ \\
\hline
\end{tabular}

O solo, classificado como latossolo amarelo coeso distróico (EMBRAPA, 1999), foi adubado e colocado em vasos $(400 \mathrm{~mL})$, semeados com 2 sementes de citros. Dez dias após a germinação, a adubação foi repetida. Após 20 dias, o patógeno foi inoculado nas plântulas pelo método da agulha, que consistiu na introdução de uma agulha esterilizada e infestada com o patógeno no caule das plântulas, seguida da colocação de algodão umedecido com água destilada e esterilizada. 0 teor de umidade do solo foi mantido por meio de irrigações periódicas. Utilizou-se um delineamento inteiramente casualizado com dezesseis tratamentos e quatro repetições. Como testemunha foi utilizado solo sem adubação.

Foram avaliadas a incidência da doença e os comprimentos da parte aérea da planta e da raiz após 10, 15 e 30 dias da inoculação. Os resultados foram comparados pelo teste de Tukey $(\mathrm{P}=0,05)$, através do programa computacional Assistat (Silva, 2009).

\section{RESULTADOS E DISCUSSÃO}

\section{Efeito da cobertura morta sobre o desenvolvimento da doença}

Resultados ilustrados, na Figura 1, demonstram que todas as coberturas mortas avaliadas apresentaram capacidade de controlar a podridão radicular causada 
por P. nicotianae em mudas de citros. As coberturas de bagaço de cana-de-açúcar e couve-folha proporcionaram o controle total da doença e tiveram resultados semelhantes ao tratamento químico. As cobertura de casca de mandioca e casca de feijão promoveram um controle parcial, porém bastante significativo da doença. Conseguiram diminuir a incidência da doença em mais de $75 \%$ (Figuras 1 e 2 ).

Figura 1. Efeito da cobertura morta sobre o desenvolvimento da podridão radicular em mudas de citros (Phytophthora nicotianae).

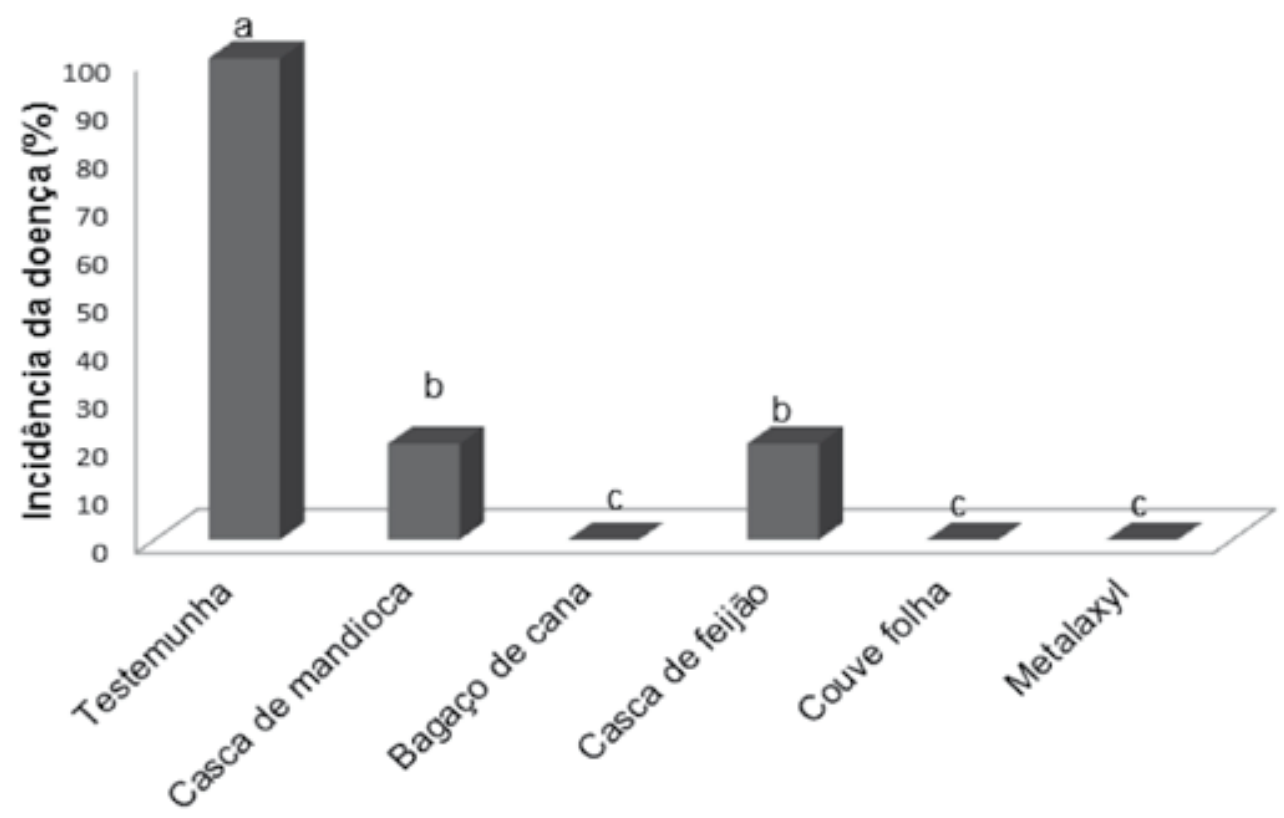

Figura 2. Efeito das coberturas mortas sobre o desenvolvimento das mudas de citros em substrato infestado com Phytophythora nicotianae. Médias seguidas da mesma letra maiúscula (altura da planta) e minúscula (comprimento de raizes) não diferem entre si pelo teste de Tukey $(P=0,05)$.

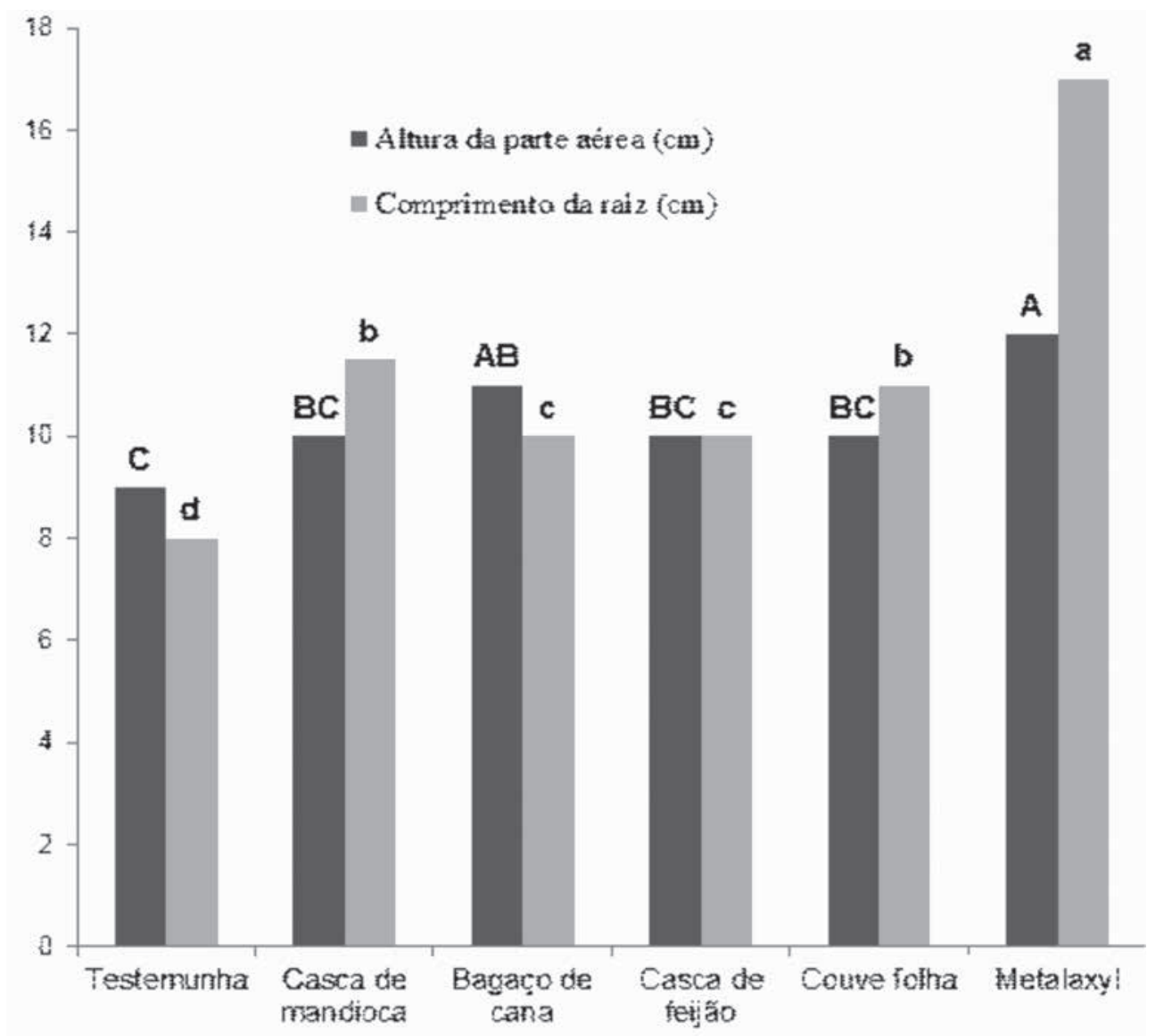


0 resultado desse trabalho concorda com Sequeira (1982), que testou resíduos orgânicos na supressão da fusariose, verificando que o bagaço de cana foi capaz de promover uma redução na incidência da murcha do fusário em bananeiras (Musa sp).

$O$ desenvolvimento das mudas de citros sofreu influência dos tratamentos. A Figura 2 mostra que na variável altura da parte aérea, a cobertura de bagaço de cana-de-açúcar proporcionou um bom desenvolvimento das plantas, semelhante ao tratamento químico, porém não diferiu dos demais resíduos, pelo teste de Tukey a $5 \%$. As coberturas de couve-folha, casca de mandioca e casca de feijão não apresentaram diferença significativa da testemunha. Na variável comprimento da raiz, todos os tratamentos diferiram da testemunha, com destaque para o tratamento com o fungicida que proporcionou o melhor desenvolvimento das raízes, seguida dos tratamentos com casca de mandioca e couve-folha e de bagaço de cana e casca de feijão.

$O$ desempenho das coberturas mortas testadas neste trabalho pode ser justificado pela capacidade de ação desses resíduos orgânicos no solo. Segundo Cadavid et al.. (1998) e Gill et al.. (1996), o uso da cobertura morta pode prover nutrientes às plantas, promover o crescimento do sistema radicular na camada superficial e reduzir as flutuações de temperatura do solo e diminuir a evaporação da água adicionada durante a irrigação, evitando a precipitação de sais na zona radicular. De acordo com Stamets e Chilton (1983), essa camada protege o substrato colonizado contra a perda de água, favorece a formação de microclima úmido, serve como reservatório de água para a cultura em crescimento e favorece 0 desenvolvimento de microrganismos benéficos. Podendo assim estar relacionado aos efeitos químicos em função dos nutrientes e/ou bioquímicos em favorecimento de antagonistas.

\section{Efeito de diferentes doses de potássio e cálcio no desenvolvimento da doença}

Os resultados demonstram que houve influência da adubação sobre o desenvolvimento da podridão radicular nas mudas de citros. A incidência da doença variou de 0 a $77 \%$, conforme as doses de potássio e cálcio (Figura 3).

Figura 3. Efeito da adubação com doses de sulfato de cálcio e fosfato de potássio sobre o desenvolvimento da podridão radicular em mudas de citros (Phytophthora nicotianae)

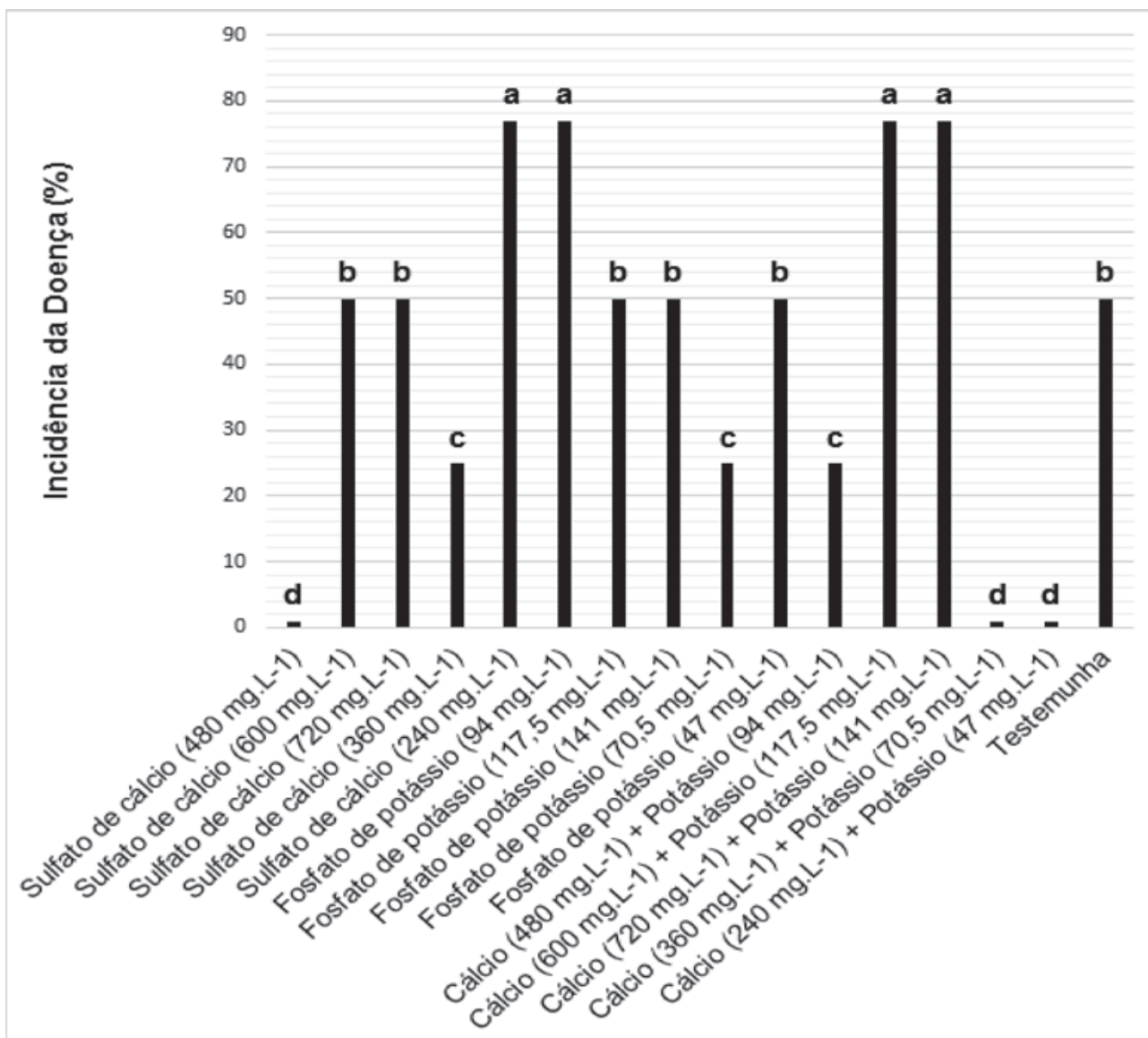


A doença foi mantida sob controle $(0 \%$ de incidência), quando as mudas de citros receberam adubação com cálcio (480 mg. $\mathrm{L}^{-1}$ ) e com a adubação associada de cálcio mais potássio, nas doses reduzidas em 25 e $50 \%$ dos referidos nutrientes ( 360 mg. L-1 $^{-1}+70,5$ $\left.\mathrm{mg} \cdot \mathrm{L}^{-1}\right)$ e $\left(240 \mathrm{mg} \cdot \mathrm{L}^{-1}+47 \mathrm{mg} \cdot \mathrm{L}^{-1}\right)$ respectivamente. Um controle de $50 \%$ da doença foi observado (25\% de incidência) ao se adubar as mudas de citros com doses de cálcio e potássio reduzidas em 25\% (360 mg.L-1 e 70,5 mg.L-1) e com a associação das doses recomendas de cálcio mais potássio $\left(480 \mathrm{mg} \cdot \mathrm{L}^{-1}+94\right.$ mg. L $^{-1}$ ) (Figura 3).

0 acréscimo de 25 e $50 \%$ de doses de cálcio (600 mg.L-1 e 720 mg.L $\mathrm{L}^{-1}$ ) e de potássio (117,5 mg.L-1 e $\left.141 \mathrm{mg} . \mathrm{L}^{-1}\right)$ e a redução de $50 \%$ da dose de potássio (47 mg. $\mathrm{L}^{1}$ ) não influenciaram a incidência da doença. As mudas apresentaram o mesmo comportamento da testemunha. Observou-se que a aplicação da dose reduzida em $50 \%$ de cálcio (240 mg. $\mathrm{L}^{-1}$ ), a aplicação da dose recomendada de potássio (94 $\mathrm{mg}^{\mathrm{L}^{-1}}$ ) e a aplicação de doses acrescidas em $25 \%$ de cálcio mais potássio (600 mg.L-1 + 117,5 mg.L L $^{1}$ ) e em $50 \%$ de cálcio mais potássio ( $720 \mathrm{mg} \cdot \mathrm{L}^{-1}+141 \mathrm{mg} \cdot \mathrm{L}^{-1}$ ) proporcionaram uma indução da podridão radicular em mudas de citros, uma vez que estas doses aumentaram sua incidência (77\%), conforme Figura 3.

A deficiência de cálcio é um fator limitante que influencia o desenvolvimento das culturas e a incidência de doenças, conforme foi relatado por Njhon et al. (1987). O que justifica a baixa eficiência no controle da podridão radicular em mudas de citros quando se utilizou doses reduzidas desse nutriente. A redução de doses de cálcio só logrou êxito quando se associou esta a adubação potássica. Nos três tratamentos que se destacaram na diminuição da incidência da podridão radicular, em todas elas, o cálcio estava presente, provando assim sua eficiência no controle da doença. Segundo Huber e Arny (1985), além do cálcio ter efeito sobre o pH do solo, ele é importante na resistência de plantas a doenças, devido ao seu papel na composição da parede celular conferindo resistência, como em plantas adultas de feijão resistentes à Rhizoctonia solani, em tomateiros resistentes à Erwinia sp., Fusarim oxysporium, Phytophthora sp. e Sclerotium rolfsii; e em mamona resistente à Botrytis $\mathrm{sp}$.

Os resultados obtidos comaadubação potássica estão de acordo com Huber e Arny (1985) que citam que, apesar do potássio ser frequentemente associado à redução da incidência e severidade de doenças de plantas, este efeito não pode ser generalizado, pois pode variar em função da sua disponibilidade no solo e interação com outros nutrientes, das condições ambientais, da suscetibilidade da planta e do patógeno envolvido. Santos et al. (2005), estudando o efeito de diferentes doses de nitrogênio em formulação com 0 potássio (na fórmula 20-00-20, de NPK) em cobertura, no crestamento gomoso do caule da melancia, constataram que a adubação com estes nutrientes não influenciou na severidade da doença.

Os efeitos negativos da adubação potássica devem ter ocorrido devido ao teor inicial de potássio contido no solo utilizado no experimento, pois segundo a interpretação de Malavolta et al. (2002), em solos com boa disponibilidade para a maioria das culturas já não se deveriam esperar respostas favoráveis após adubação. 0 excesso de concentração local de cloreto de potássio prejudicou o crescimento das plantas, pois embora este adubo não tenha sido empregado em contato com as mudas, ficou localizado no percurso de suas raízes primárias e pode ter provocado danos salinos às plantas (Raij et al., 2007). Tal dano é manifestado em plantas de pinhão manso na redução da altura de plantas, do diâmetro caulinar e da área foliar, sendo esta a variável de crescimento mais afetada nesta condição (Nery et al., 2009).

Segundo Borges-Perez et al. (1983) e Cordeiro (1988) que obtiveram resultados semelhantes aos deste trabalho, na cultura da bananeira, em relação aos sintomas do mal-do-panamá, em solos onde 0 nível de potássio é excessivamente alto em relação ao cálcio e magnésio as plantas apresentam sintomas de doenças. Os valores da relação $\mathrm{K} / \mathrm{Mg}$, nesses solos, foram estatisticamente superiores aqueles verificados em solos com plantas sadias. Esses dados mostram que é muito importante manter o equilíbrio entre os minerais no solo.

As doses de cálcio e potássio não influenciaram o desenvolvimento das mudas de citros. Nenhum tratamento apresentou diferença significativa comparada à testemunha.

No presente estudo, ficou comprovada a importância do uso da cobertura morta e da adubação no controle da podridão radicular ( $P$. nicotianae) em mudas de citros. Nesta condição, o uso de coberturas como folha de couve ou bagaço de cana-de-açúcar ou da adubação com doses recomendadas de sulfato 
de cálcio e doses reduzidas da mistura de sulfato de cálcio e fosfato de potássio (25 e 50\%) poderão atender as expectativas da produção de mudas de citros livres da podridão radicular, diminuindo os custos com a aplicação de defensivos. Estudos avançados envolvendo a integração de coberturas morta e adubações para o controle de doenças devem ser conduzidos com o intuito de oferecer informações para uma melhor indicação e aplicação dos mesmos como parte de uma tática de manejo integrado de doenças na cultura dos citros.

\section{REFERÊNCIAS BIBLIOGRÁFICAS}

Blok, W.J.; Lamers, J.G.; Termorshuizen, A.J.; Bollen, G.J. Control of soilborne plant pathogens by incorporating freesh organic amendments followed by tarping. Phytopathology, 2000, 90, 3, 253-259.

Borges-Pérez A, Trujillo J.C.I, Gutierrez-Jerez F., Angulorodriguez D.. Estudio sobre el mal de Panamá em las Islas Canarias. II - Influencia de los desequilibrios nutritivos P-Zn Y K-Mg del suelo, en la alteracion de los mecanismos de resistência de la plantanema (Ca-vendish enana) al Mal do Panamá. Fruits. 1983, 38, 755-758.

Boten, M.; Neves, E.M. Citricultura brasileira: aspectos econômicos. In: Mattos Junior, D; Negri, J.D.; Pio, R.M.; Pompeu Junior, J.(Ed.). Campinas: IAC/Fundag. 2005. 926p.

Cadavid, L.F.; El-Sharkawy, M.A.; Acosta, A; Sanches, T. Long-term effects of mulch, fertilization and tillage on cassava grown in sandy soils in Northern Colombia. Field, 1998, 57, 45-56.

Castro, L.M.. Isolamento, cultura de protoplasmo e regeneração de plântulas de laranja doce (Citrus sinenses L. Osbeck). Citricultura Anual. 2009, 18-19.

Cordeiro, R. O saturnismo em Bauru: Saúde do Trabalhador. In: Pimenta,A. L.; Costa Filho, D.(Ed.). São Paulo: Hucitec. 1988, 47-83.

Feichtenberger, E.; Bassanezi, R. B.; Spósito, M. B.; Belasque JR, J. Doenças dos citros. In: BERGAMIN FILHO, A. E et al.; Manual de Fitopatologia - doenças das plantas cultivadas. Sao Paulo: Ed. Agronômica Ceres. 2005, 2, 239-269.
Gill, K.S.; Gajri, P.R.; Chaudhary, M.R.; Singh, B. Tillage, mulch, and irrigation effects on corn (Zea mays L.) in relation to evaporative demand. Soil Tillage Research, 1996, 39, 213-227.

Huber, D.M.; Arny. Interaction of potassium with plant disease. Annual Review Phytopatology, 1985, 12, 139-65.

IBGE, Levantamento sistemático da produção agrícola. Disponivel em: http://www.ibge.gov.br/home/estatistica/ indicadores/agropecuaria/lspa/defaulttab.sht. Acesso em: 31 de maio de 2011.

Malavolta, E.; Pimentel-Gomes, F.; Alcarde, J. C. Adubos e adubações. São Paulo: NOBEL. 2002, 200 p.

Marschner, $\mathrm{H}$. Relations hip between mineral nutrition and plant disease and pests. In: MARSCHNER, H. (Ed.) Mineral nutrition of higher plants. New York: Academic Press. 1996, 369-390.

Marschner, $\mathrm{H}$. Mineral nutrition of higher plants. New York: Academic Press. 1995.

Nery, A. R.; Rodrigues, L. N.; Silva, M. B. R.; Fernandes, P. D.; Chaves, L. H. G.; Dantas Neto, J.; Gheyi, H. R. Crescimento do pinhão-manso irrigado com águas salinas em ambiente protegido. Revista Brasileira de Engenharia Agrícola e Ambiental, 2009, 13, 5, 551-558.

Neves, M. F.; Trombin,V. G.; Milan,P.; Lopes,F. F.; Cressoni,F.; Kalaki, R. O retrato da citricultura brasileira. Ribeirão Preto: Markestrat, 2011, 16 p.

Njhon, B.O.; Enwezor, W.O.; Onzenakwe, B.I. Calcium deficiency identified as an important factor limiting maize growth in acid ultisols of Eastern Nigeria. Fertilizer Research, 1987, 14, 113-124.

Pipolo,V.C.; Assis, J.S.; Garcia,I.P. Adubação e resistência de plantas a doenças e nematóides. Semina Ciência Agrícola, 1993, 14, 1, 40-46.

Raij, B. V. Fertilidade do solo e adubação. Piracicaba: Ceres, 1991. 343p.

Santos, GR; Café-Filho, AC; Saboya, LMF. Controle químico do crestamento gomoso do caule em melancia. Fitopatologia Brasileira, 2005, 30, 155-163. 
Sequeira, L. Influence of organic Amendments on Survival of Fusarium oxusporum $\mathrm{f}$. Cubense in the soil. Phytopathology, 1982. 52, 10, 976-982.

Silva, F. A.S. ASSISTAT. Universidade Federal de Campina Grande-PB. 2009

Sistema Brasileiro de Classificação de Solos. 3 ed. Revisão ampliada - Brasília, DF: Embrapa, 2013.353 p
Stamets, P.; Chilton, J.S. The mushroom cultivator. Washington: Agrikon Press, 1983, 415p.

Zauza, E. A.V.; Alfenas, A.C.; Maffia, L. A.; Silveira, S. F.; Fernandes, D. Flutuação de inóculo de Rhizoctonia spp. e Cylindrocladium spp. em jardim clonal de Eucalyptus grandis, sob diferentes tipos de cobertura morta. Summa Phytopathologica, 2001, 27, 2, 213-216. 